\title{
Matrine induction of reactive oxygen species activates p38 leading to caspase-dependent cell apoptosis in non-small cell lung cancer cells
}

\author{
CAIHONG TAN ${ }^{1,2}$, XIAOQIANG QIAN ${ }^{2}$, RONGDI JIA ${ }^{2}$, MIN WU $^{3}$ and ZHONGQIN LIANG \\ ${ }^{1}$ College of Pharmacy, Soochow University, Suzhou, Jiangsu 215123; Departments of ${ }^{2}$ Pharmacy and \\ ${ }^{3}$ Neurosurgery, The Affiliated Hospital of Jiangsu University, Zhenjiang, Jiangsu 212001, P.R. China
}

Received June 2, 2013; Accepted August 22, 2013

DOI: $10.3892 /$ or.2013.2727

\begin{abstract}
Non-small cell lung carcinoma (NSCLC) is one of the most refractory cancers in the clinic; it is insensitive to chemotherapy and is usually excised. However, screening natural compounds from herbs is also considered a possible method for its therapy. In the present study, we investigated whether matrine, a natural compound isolated from Sophora flavescens Ait. and exerting an inhibitory effect on lung cancer cells, also indicates inhibition on NSCLC cells and elucidated its molecular mechanism. Firstly, it is confirmed that matrine induces apoptosis of human NSCLC cells with anti-apoptotic factors inhibited and dependent on caspase activity. In addition, we found that matrine increases the phosphorylation of p38 but not its total protein, and inhibition of the p38 pathway with SB202190 partially prevents matrine-induced apoptosis. Furthermore, matrine generates reactive oxygen species (ROS) in a dose- and time-dependent manner, which is reversed by pretreatment with N-acetyl-L-cysteine (NAC). Additionally, inhibition of cell proliferation and increase of phosphorylation of p38 was also partially reversed by NAC. Collectively, matrine activates p38 pathway leading to a caspase-dependent apoptosis by inducing generation of ROS in NSCLC cells and may be a potential chemical for NSCLC.
\end{abstract}

\section{Introduction}

Lung cancer is the leading type of cancer worldwide with high mortality rates in men and women alike, at 29 and $26 \%$, respectively (1). Non-small cell lung carcinoma (NSCLC) is the most frequent subtype, representing $~ 85 \%$ of all cases, and most patients have locally advanced or distant metastatic

Correspondence to: Professor Zhongqin Liang, College of Pharmacy, Soochow University, 199 Renai Road, Suzhou, Jiangsu 215123, P.R. China

E-mail: liangzqs@163.com

Key words: matrine, caspase-dependent apoptosis, p38, reactive oxygen species, non-small cell lung cancer disease at the time of presentation (2). Although NSCLCs are relatively insensitive to chemotherapy, compared to small cell carcinoma, and are primarily treated by surgical resection with curative intent (3), chemotherapy is increasingly being used both pre-operatively (neoadjuvant chemotherapy) and post-operatively (adjuvant chemotherapy) $(3,4)$. Most researchers believed that anticancer drugs for NSCLC may be found from natural plants (5). Several natural compounds have been found to be effective in inhibiting NSCLC in the lab and in the clinic (5). Among them, paclitaxel, the most typical compound from yew has been approved to be used clinically for cancer patients. A number of other herbal compounds such as xanthatin, lycobetaine, resveratrol, ursolic acid and lycorine are also being investigated for NSCLC (5).

Sophora species (Leguminosae), an important source of Chinese herbal drugs, has been used widely throughout China for thousands of years. As a traditional Chinese herb, the root of Sophora flavescens Ait. (Kushen) has long been applied for the therapy of numerous diseases, such as hepatitis (6), cardiac diseases (7) and skin diseases (8). Quinolizidine alkaloids have been found to be its chief active components in Sophora flavescens including matrine, oxymatrine, sophocarpine, sophoridine and other alkaloids (9). Basic and clinical studies have shown that these alkaloids possess a variety of pharmacological effects including anti-inflammation $(10,11)$, immunity-regulation (12), antivirus (6) and antitumor action (13-15).

Matrine, with a molecular weight of 248.4 (Fig. 1), is the major quinolizidine alkaloid and has been considered a major bioactive component of the dried roots of Sophora flavescens. It has been found that matrine possesses a wide range of pharmacological activities, and its antitumor activity has attracted considerable attention in recent years. Cumulative data have demonstrated that matrine exerts anticancer effect on many series of human cancer cells including lung cancer (16), hepatoma (16), breast cancer (17), pancreatic cancer (18), prostate cancer $(19,20)$ and colon cancer $(21)$. Upregulation of protein E2F-1 and activation of caspases contribute to matrine-induced leukemia cell proliferation inhibition and apoptosis (15). For MDA-MB-231 breast cancer cells, matrine has been demonstrated to inhibit cell proliferation by reducing the ratios of $\mathrm{Bcl}-2 / \mathrm{Bax}$ protein and mRNA levels 
and to reduce cancer cell invasion by inhibiting the VEGFAKT-NF- $\mathrm{KB}$ signaling pathway, as well as by inactivating MMPs (22).

In particular, several efforts focused on how matrine inhibits lung cancer $(16,23,24)$, suggesting that it may be a potential anticancer agent for lung cancer. Additionally, the results that matrine in combination with anticancer drugs significantly inhibited SPCA-1 (24) or A549 cells (23) indicated its potent inhibitory effect on NSCLC. However, although suppressing MAPK/ERK signal transduction was demonstrated to be involved in matrine resisting NSCLC (23), no other mechanisms were confirmed. In this study, we found that matrine caused NSCLC apoptosis due to induction of ROS generation and subsequent activation of MAPK/p38 signaling pathway.

\section{Materials and methods}

Materials. Matrine was from Tianyuan Biological Agent Plant (Xi'an, Shaanxi, China; purity, 98\%). RPMI-1640 was purchased from Mediatech (Herndon, VA, USA). Fetal bovine serum (FBS) was supplied by HyClone (Logan, UT, USA), and $0.05 \%$ Trypsin-EDTA was from Invitrogen Life Technologies (Grand Island, NY, USA). 3-(4,5-Dimethylthiazol-2-yl)-2,5diphenyltetrazolium bromide (MTT) was from Sigma-Aldrich (St. Louis, MO, USA). Annexin V-FITC Apoptosis Detection kit I was from BD Biosciences (San Diego, CA, USA). Enhanced chemiluminescence solution was from PerkinElmer Life Sciences (Boston, MA, USA). Carbobenzoxy-valyl-alanylaspartyl-[O-methyl]-fluoromethylketone (Z-VAD-FMK) was purchased from ALEXIS Biochemicals Corporation (San Diego,CA, USA). The MAPK/p38 pathway inhibitor SB202190 was obtained from LC Laboratories (Woburn, MA, USA). The following antibodies were used: p38, phospho-p38, caspase-3, PARP, Bcl2, BAD (all from Santa Cruz Biotechnology, Inc., Santa Cruz, CA, USA), $\beta$-actin (Sigma).

Cell lines and culture. Human NSCLC cells A549, NCI-H358 were obtained from the cell bank of the Chinese Academy of Sciences (Shanghai, China). A549 and NCI-H358 cells were grown in antibiotic-free RPMI-1640 supplemented with 10\% FBS and incubated in a humid incubator $\left(37^{\circ} \mathrm{C}, 5 \% \mathrm{CO}_{2}\right)$.

Cell proliferation assay. Cells dispersed evenly in medium were seeded in a 6 -well plate with a density of $1 \times 10^{5}$ cells/well. Next day, cells were treated with various concentrations of matrine $(0-100 \mu \mathrm{M})$ for $48 \mathrm{~h}$. After incubation, MTT $(5 \mathrm{mg} / \mathrm{ml})$ was added to each well, followed by a $4 \mathrm{~h}$ incubation. The medium was discarded and $150 \mu 1$ of dimethyl sulfoxide (DMSO) was added into each well, and incubated for $20 \mathrm{~min}$. The optical density (OD) in $570 \mathrm{~nm}$ was measured by a BioTek multilabel counter. The cell proliferation inhibition index was calculated according to the formula: $\left(\mathrm{OD}_{\text {control }}-\mathrm{OD}_{\text {matrine }} / \mathrm{OD}_{\text {control }}\right) \times 100 \%$. The experiments were repeated 3 times.

Cell apoptosis analysis. A549 cells were seeded in 6-well plates at a density of $2 \times 10^{6}$ cells/dish in RPMI- 1640 supplemented with $10 \% \mathrm{FBS}$ and were grown overnight at $37^{\circ} \mathrm{C}$ in a humidified incubator with $5 \% \mathrm{CO}_{2}$. Cells were treated with matrine $(0-50 \mu \mathrm{M})$ for $48 \mathrm{~h}$, followed by apoptosis assay using



Figure 1. The structure of matrine.

the Annexin V-FITC Apoptosis Detection kit I. Cells without treatment were used as a control.

Caspase-3/7 activity assay. Caspase-3/7 activity was measured by the Sensolyte Homogeneous AMC caspase-3/7 assay kit (AnaSpec Systems, San Jose, CA, USA) according to the manufacturer's instructions. Briefly, cells were seeded in black 96-well plates and cultured for $24 \mathrm{~h}$ followed by treatment with matrine $(0-50 \mu \mathrm{M})$ for $24 \mathrm{~h}$. Then, $50 \mu \mathrm{l} /$ well of caspase-3/7 substrate solution was added into each well. The reagents were mixed completely by shaking and the reaction was incubated at room temperature for $1 \mathrm{~h}$. Finally, fluorescence intensity was measured at $\mathrm{Ex} / \mathrm{Em}=354 / 442 \mathrm{~nm}$ using a BioTek multilabel counter.

ROS assay. A549 and NCI-H358 cells were respectively seeded at a density of $1 \times 10^{4}$ cells/well in 96-well plates. Cells were incubated in the presence of various concentrations of matrine $(0-50 \mu \mathrm{M})$ for $24 \mathrm{~h}$ or $30 \mu \mathrm{M}$ matrine for the indicated time (0-24 h) with 6 replicates of each treatment followed by loading with $\mathrm{CM}-\mathrm{H}_{2}$ DCFDA following the manufacturer's protocol. In some cases, cells were pretreated with $\mathrm{N}$-acetyl-L-cysteine (NAC; $5 \mathrm{mM}$ ) for $1 \mathrm{~h}$, and then treated with/without matrine (30 and $50 \mu \mathrm{M}$ ) for $24 \mathrm{~h}$, followed by loading with CM- $\mathrm{H}_{2}$ DCFDA for $2 \mathrm{~h}$. Fluorescent intensity was measured at $E x / E m=485 / 535 \mathrm{~nm}$ using a BioTek multilabel counter.

Western blot analysis. Treated cells were briefly washed 2 times with cold PBS. Cells were lysed in the lysis buffer [50 mM Tris, pH 7.2; $150 \mathrm{mM} \mathrm{NaCl} ; 1 \%$ sodium deoxycholate; $0.1 \%$ sodium dodecyl sulfate (SDS); $1 \%$ Triton X-100; $10 \mathrm{mM}$ $\mathrm{NaF} ; 1 \mathrm{mM} \mathrm{Na} \mathrm{VO}_{4}$; protease inhibitor cocktail $(1: 1,000$; Sigma)]. Lysates were sonicated for $2 \times 15 \mathrm{sec}$ and centrifuged at $13,000 \mathrm{x}$ g for $2 \mathrm{~min}$ at $4^{\circ} \mathrm{C}$. Protein concentration was determined by bicinchoninic acid assay with bovine serum albumin as standard (Pierce Biotechnology, Inc., Rockford, IL, USA). Western blotting was carried out as previously described. The antibodies used were described above.

Statistical analysis. The results are expressed as the mean values \pm standard error (means $\pm \mathrm{SE}$ ). A one-way analysis of variance (ANOVA) was used to examine differences among the matrine groups. Differences were considered statistically significant when $\mathrm{P}<0.05$. 


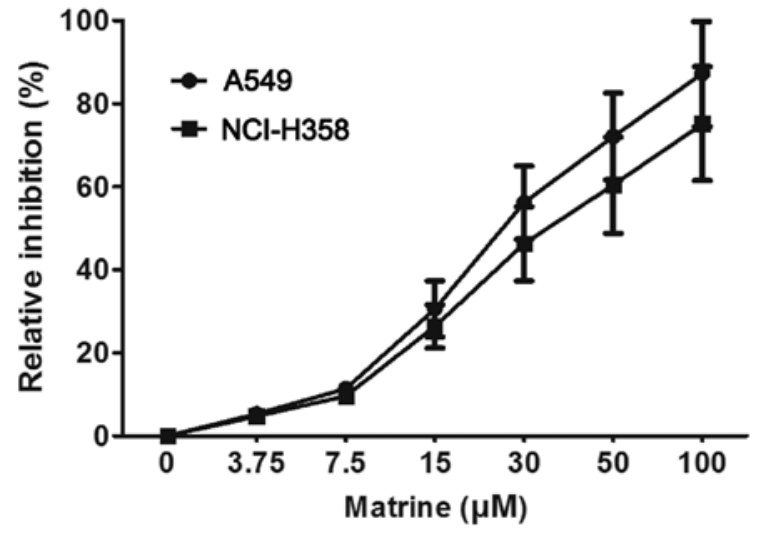

Figure 2. Matrine inhibits non-small cell lung cancer cells. A549 and NCIH358 cells grown in 6 -well plates $\left(1 \times 10^{4}\right.$ cells/well) were treated with the indicated concentrations of matrine $(0-100 \mu \mathrm{M})$ for $48 \mathrm{~h}$. Cell proliferation was evaluated using MTT assay. Absorbance at $490 \mathrm{~nm}$ was determined with a BioTek multilabel counter.

\section{Results}

Matrine inhibits proliferation and induces apoptosis in NSCLC cells. As shown in Fig. 2, relative inhibition curves induced by matrine in two lung cancer cells increased in a dose-dependent manner. With a logarithmic regression analysis, the concentration of matrine which results in $50 \%$ of maximal proliferation inhibition $\left(\mathrm{IC}_{50}\right.$ ) of cells was calculated. The $\mathrm{IC}_{50}$ value was $\sim 25.0 \mu \mathrm{M}$ for A549 cells, and $\sim 34.6 \mu \mathrm{M}$ for NCI-H358 cells.

To examine whether matrine-inhibited cell proliferation is related to induction of cell apoptosis, Annexin V-FITC and PI staining were used. As indicated in Fig. 3, the rate of apoptotic cells increased significantly (more than $\sim 40 \%$ ) from $11.8 \%$ of control to 28.4, 42.3 and $43.3 \%$, in A549 cells treated with matrine (15, 30 and $50 \mu \mathrm{M})$ (Fig. 3). Matrine clearly induced cell apoptosis.

Caspase and apoptotic factors involved in matrine-induced cell apoptosis. Apoptosis is a complicated process involving several factors, and is divided into 2 different types; one is dependent on caspase, the other is not. To understand which type of apoptosis matrine induces, two key molecular proteins indicating apoptosis were detected including caspase- 3 and PARP by western blot assay. The results indicated that the $17 \mathrm{kD}$ cleaved-caspase-3, regarded as the marker of caspase activation in apoptosis, was expressed, as well as the $89 \mathrm{kD}$ cleaved-PARP (Fig. 4A). This suggested that matrine-induced apoptosis was dependent on caspase. To further confirm this, the caspase-3/7 activity was examined using caspase-3/7 assay kit. As shown in Fig. 4B, the caspase-3/7 activity showed significant change in A549 cells with the treatment of the indicated concentration of matrine. Additionally, Z-VAD-FMK, a caspase inhibitor, pretreated for half an hour in A549 cells also reversed matrine-induced inhibition (Fig. 4C). Bcl2, exerting an anti-apoptotic function in response to a wide range of apoptotic stimuli, was also inhibited in A549 cells by matrine, while BAD, a pro-apoptotic factor of the Bcl-2 family that promotes cell death by displacing Bax from binding to Bcl-2 and Bcl-xL, expressed more by induction of matrine than the control. Taken together, matrine-induced cell apoptosis was dependent on caspase.

Matrine activates $M A P K / p 38$. Since matrine triggered a caspase-dependent apoptosis course, it is necessary to further indicate which upstream pathways regulate it. Here, we found p38 was an important pathway to mediate matrine-induced cell apoptosis. After A549 cells were exposed to matrine $(0-50 \mu \mathrm{M})$
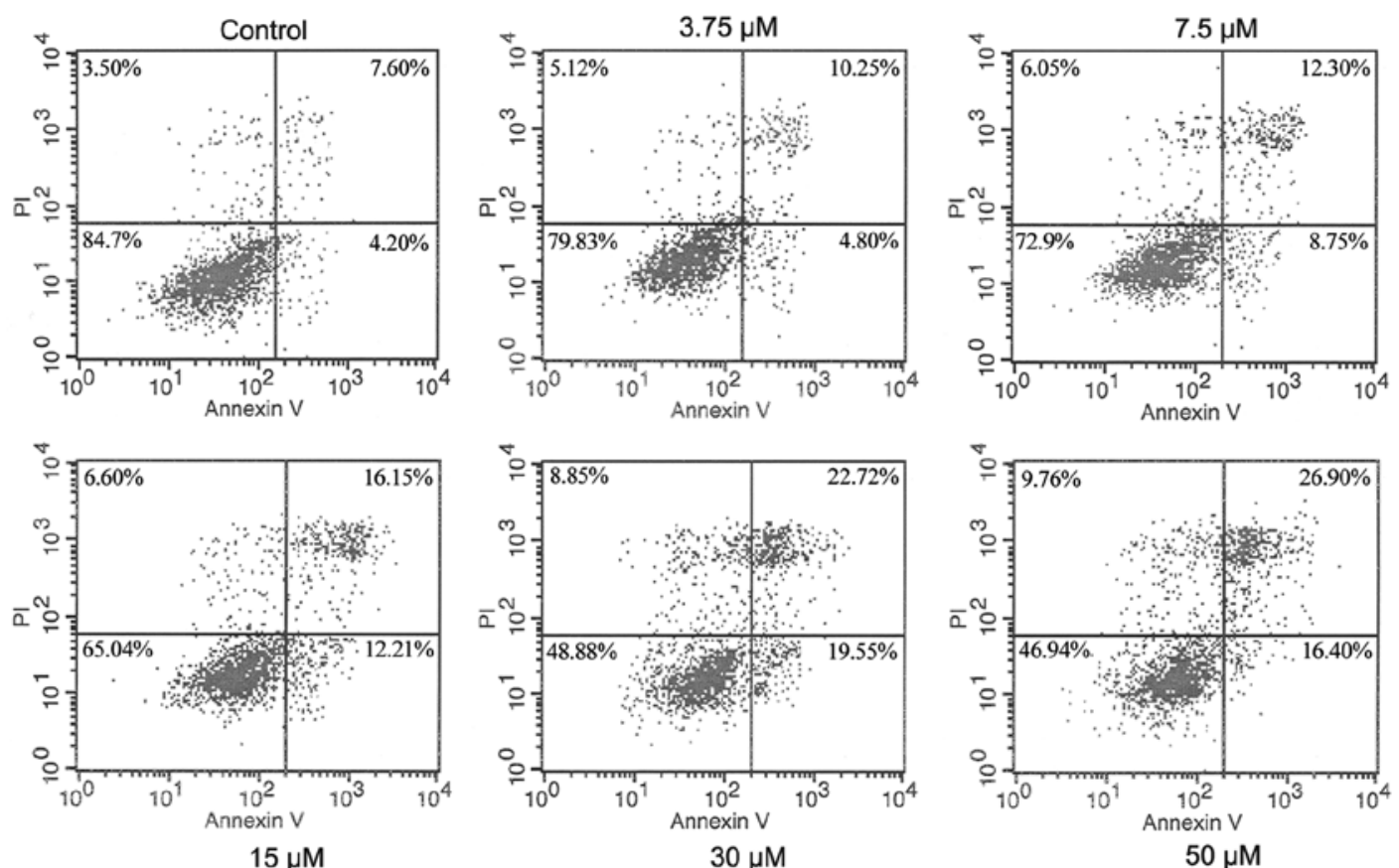

Figure 3. Matrine induces non-small cell lung cancer cell apoptosis. A549 cells grown in 6-well plates (1x10 5 cells/well) were treated with the indicated concentrations of matrine $(0-50 \mu \mathrm{M})$ for $48 \mathrm{~h}$, then stained with Annexin V-FITC and propidium iodide (PI), followed by flow cytometry analysis. 

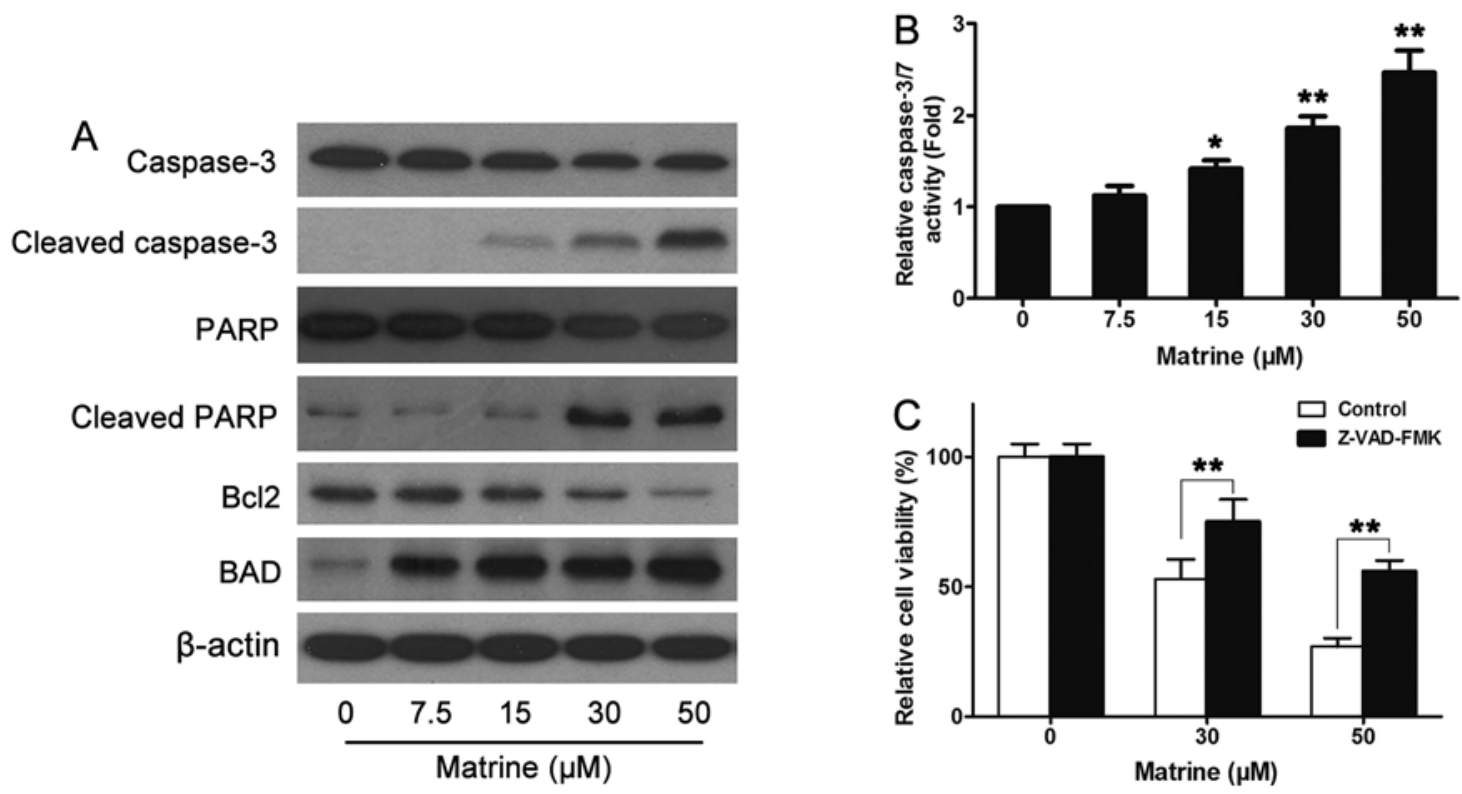

Figure 4. Matrine inhibits anti-apoptotic factors dependent on caspase. (A) A549 cells were grown in 6-well plates and treated with matrine at the indicated concentrations for $8 \mathrm{~h}$, followed by western blot analysis with the indicated antibodies including caspase-3, PARP, Bcl2, BAD, $\beta$-actin. (B) A549 cells were seeded in black 96 -well plates and cultured for $24 \mathrm{~h}$ followed by treatment with matrine $(0-50 \mu \mathrm{M})$ for $24 \mathrm{~h}$. Then, $50 \mu 1 /$ well of caspase-3/7 substrate solution was added into each well. The reagents were mixed completely by shaking and the reaction was incubated at room temperature for $1 \mathrm{~h}$; fluorescence intensity was measured at $\mathrm{Ex} / \mathrm{Em}=354 / 442 \mathrm{~nm}$ using a BioTek multilabel counter. (C) A549 cells were grown in 6-well plates and treated with matrine or pretreated with Z-VAD-FMK at the indicated concentrations for $24 \mathrm{~h}$.
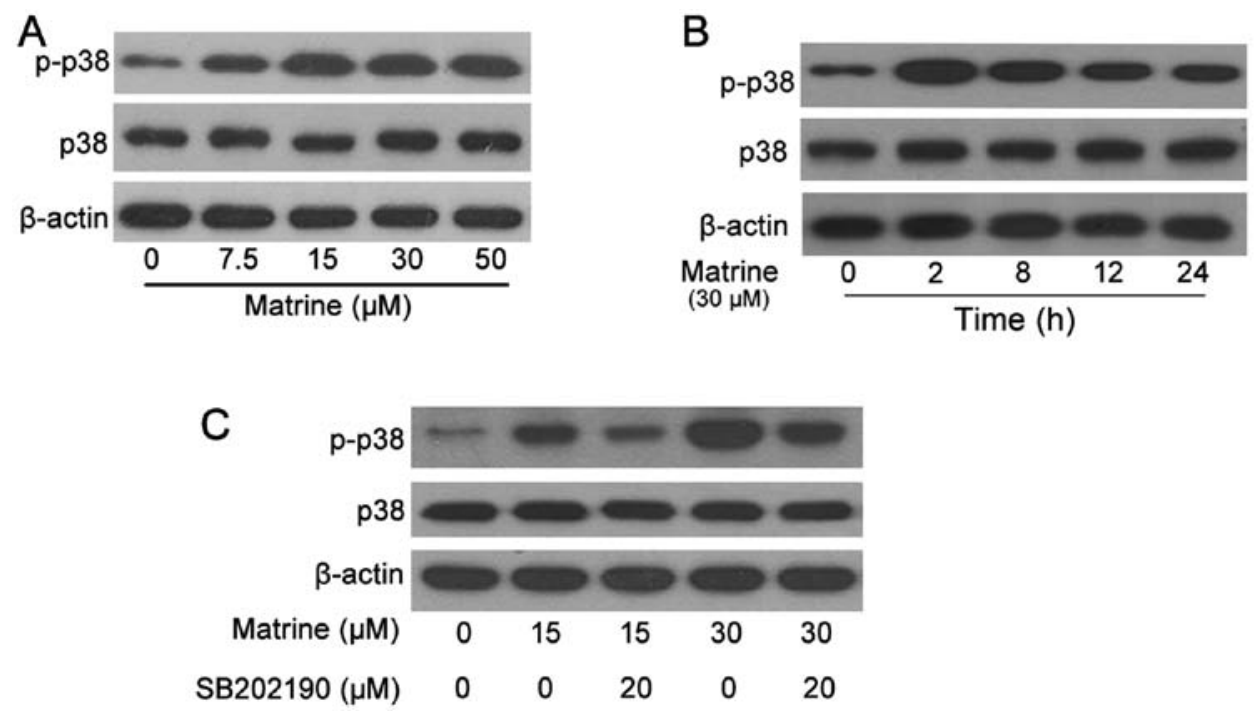

Figure 5. Matrine activates MAPK p38 pathway in non-small cell lung cancer cells. (A and B) A549 cells were grown in 6-well plates and treated with matrine at the indicated concentrations for $8 \mathrm{~h}$, followed by western blot analysis with the indicated antibodies. (C) A549 cells pretreated with or without SB202190 $(10 \mu \mathrm{M})$ for $30 \mathrm{~min}$, were treated with matrine $(0,15,30 \mu \mathrm{M})$ for $8 \mathrm{~h}$, followed by western blot analysis with the indicated antibodies.

for $8 \mathrm{~h}$, the cellular lysates were subjected to western blot analysis and the results revealed that matrine significantly increased the phosphorylation of $\mathrm{p} 38$ starting from $7.5 \mu \mathrm{M}$ (Fig. 5A). With the treatment of $30 \mu \mathrm{M}$ matrine for the indicated time $(0-24 \mathrm{~h})$, the phosphorylation of $\mathrm{p} 38$ was also upregulated and was expressed the highest at $2 \mathrm{~h}$, before decreasing gradually to $24 \mathrm{~h}$ (Fig. 5B). Therefore, matrine activates the p38 pathway.

The MAPK inhibitors were generally used to further ascertain whether the tested samples functioned via this pathway. SB202190, blocking p38, pretreated the A549 cells for $1 \mathrm{~h}$ following the 8 - $\mathrm{h}$ treatment of matrine, the upregulated phosphorylation of p38 was partially reversed by the inhibitors (Fig. 5C). From the cell counting data, A549 cells treated with matrine plus SB202190 showed more viability than those without inhibitors. This indicated that activation of the p38 pathway is necessary for matrine inhibition of cell apoptosis.

Matrine induces ROS generation. It is well known that ROS have a cellular signaling role in several biological systems, both in animals and plants, and in most stress-related cell progress. ROS induce programmed cell death or necrosis, induce or suppress the expression of many genes, and activate 

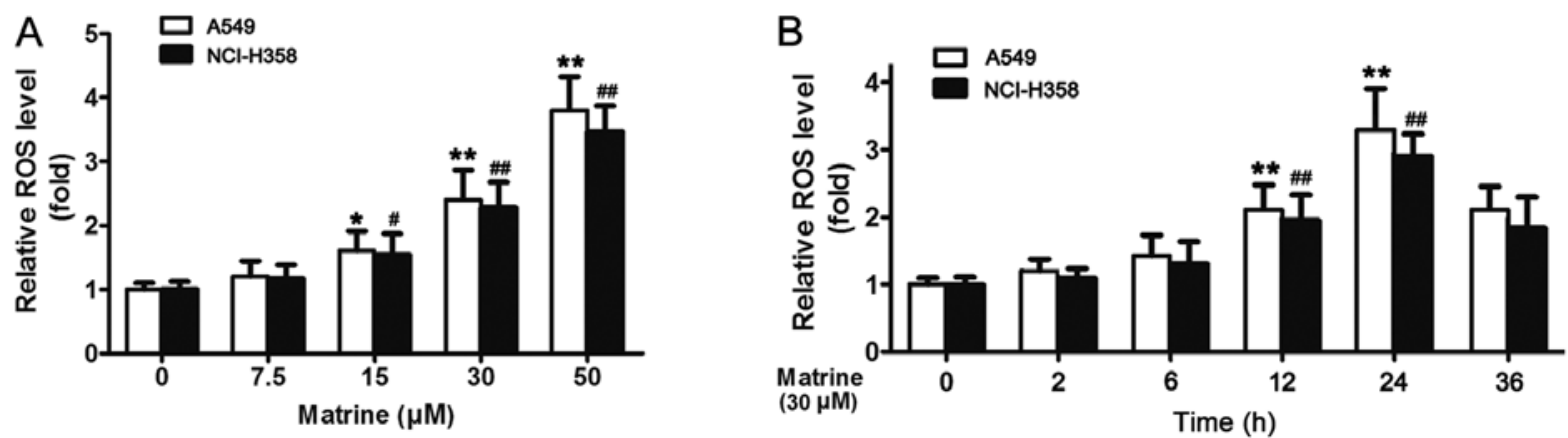

Figure 6. Matrine induces reactive oxygen species (ROS) generation in non-small cell lung cancer cells in a concentration- and time-dependent manner. A549 or NCI-H358 cells were seeded in 96-well plates, then treated with matrine at indicated concentrations for (A) $24 \mathrm{~h}$ or (B) with $30 \mu \mathrm{M}$ for the indicated time. ROS in the cells were detected using CM- $\mathrm{H}_{2}$ DCFDA reagent kit. Results are presented as means $\pm \mathrm{SE}, \mathrm{n}=6 .{ }^{*}, \| \mathrm{P}<0.05,{ }^{* *, \# \#} \mathrm{P}<0.01$, difference vs. control $(0 \mu \mathrm{M}$ matrine).


Figure 7. The apoptotic effect of matrine is attributed to induction of reactive oxygen species (ROS). (A-C) N-Acetyl-L-cysteine (NAC), an antioxidant and scavenger of ROS, reserved matrine induction of ROS and conferred resistance to matrine inhibition of cell viability. A549 cells grown in 96-well or 6-well plates, were pretreated with or without NAC $(5 \mathrm{mM})$ for $30 \mathrm{~min}$ and then treated with matrine at the indicated concentrations for $24 \mathrm{~h}$, followed by (A) ROS assay, or (B) cell counting assay (C) or western blotting. Results are presented as means $\pm \mathrm{SE}, \mathrm{n}=6 .{ }^{*} \mathrm{P}<0.05,{ }^{* * *} \mathrm{P}<0.01$, difference vs. control ( $0 \mu \mathrm{M}$ matrine).

cell signaling cascades, such as the mitogen-activated protein kinases. Therefore, whether matrine activating MAPK is also due to inducing ROS or related to other factors, remains to be confirmed. CM- $\mathrm{H}_{2}$ DCFDA, a stable non-fluorescent molecule, specially designed to detect ROS through oxidized by oxygen radicals to form fluorescent molecule excitated by specific wavelength lights was used to measure the level of ROS in A549 cells treated with matrine; the data showed that matrine induced ROS generation in a dose- and time-dependent manner (Fig. 6A and B).

$N A C$ reverses the effect of matrine on ROS, p38 and cell viability. With the exception of ROS, several other factors including stress, EGF, radicals, IL-1, integrin can act on the MAPK pathway leading to cell proliferation, apoptosis, necrosis. Hence, it would be confirmed that matrine activating p38 pathway is mediated through inducing ROS generation if clearing ROS can reverse all or at least part of the effects mediated by matrine. NAC, a powerful antioxidant to clear the ROS, was used, then ROS generation, MAPKs pathway and cell viability were revaluated. The results of Fig. 7 suggest that ROS generation induced by matrine was completely reversed by NAC (5 mM) (Fig. 7A); second, matrine-induced increased expression of phosphorylation of p38 was also significantly reversed by NAC (Fig. 7B); third, most of the A549 cells were alive after treatment with matrine plus NAC (Fig. 7C). Based on the above results, matrine acting on the MAPK pathway is inevitably dependent on ROS. 


\section{Discussion}

Non-small cell lung cancer (NSCLC) is any type of epithelial lung cancer other than small cell lung carcinoma (SCLC). It is further distinguished into three subtypes: squamous cell carcinoma, large cell carcinoma and adenocarcinoma $(2,25)$. Since the early 2000s, a greater understanding of the molecular biology of NSCLC has led to revolutionary treatment of these carcinomas (26).

Most SCLCs acquire multi-drug resistance, while NSCLCs tend to be intrinsically resistant to chemotherapy (27). Less than $5 \%$ of SCLC patients currently survive five years past initial diagnosis, but $15 \%$ of patients with NSCLC survive 5 years (27). Historically, response rates rarely exceeded $20 \%$ prior to the development of cisplatin, with an increase to $20-40 \%$ during the cisplatin-combination era. In the post-cisplatin era, new antitumor drugs such as gemcitabine, vinorelbine, paclitaxel and docetaxel have been improved with the intention of increasing response rates to as high as $50-60 \%(28,29)$. Except for the above-mentioned chemicals, several compounds from natural herbs including lycobetaine, resveratrol, indirubin, ursolic acid have been considered potential anticancer drugs for NSCLC (5). Matrine, an alkaloid from Sophora flavescens Ait., was also found to be an anticancer agent, and possibly showed higher inhibition on lung cancer cells than any other cancer cells. Additionally, matrine inhibition of lung carcinoma angiogenesis via suppression of MAPK/ERK signal transduction suggested that the MAPK signaling pathway plays a critical role in it (23).

It is well known that MAPKs contain three main family members, respectively known as the c-Jun NH2-terminal kinase (JNK), the p38 and the extracellular signal-regulated kinase (ERK). Each of the MAPK cascade pathways works by the same three-tier manner. The MAPK kinase kinase (MAPKKK), activated by environmental or extracellular stimulus, activates MAPK kinase (MAPKK) which sequentially activates MAPK through gradient phosphorylation. Phosphorylation of the MAPK leads to activation of the corresponding substrates, which regulate the transcription factor and control cell proliferation, differentiation, motility and apoptosis $(30,31)$.

Previously, MAPK/ERK was demonstrated to be involved in matrine suppressing HUVEC cell migration induced by A549 cancer cells. Matrine inhibition of phosphorylation of ERK induces antiangiogenic effects leading to the elimination of lung carcinoma (23). Thus, in the present study, we focused on elucidating whether MAPK/p38 also involves matrine induction of apoptosis in NSCLC and how it acts.

p38, known as stress-activated protein kinases (SAPKs), is widely expressed in most tissues and participates in several different stress signaling pathways that control a spectrum of cellular processes $(31,32)$. Most of the data demonstrated that activation of the p38-MAPK signaling induced cell apoptosis and death in cancer cells $(33,34)$. Increase of caspase-3/7 activity and overexpression of cleaved caspase- 3 and cleaved PARP make it clear that matrine induces a caspase-dependent apoptosis in NSCLC cells, as well as Z-VAD-FMK, a cellpermeant caspase inhibitor that irreversibly binds to the catalytic site of caspase, can reverse inhibition of proliferation in part. Then, matrine significantly increasing phosphoryla- tion of p38 disclosed p38 also mediates matrine induction of apoptosis.

Free radicals and reactive molecules containing oxygen are collectively known as ROS and induce oxidative stress in cells (35). ROS, such as hydrogen peroxide $\left(\mathrm{H}_{2} \mathrm{O}_{2}\right)$ and superoxide $\left(\mathrm{O}^{2-}\right)$, are found higher in most tumors and cancer cells than in normal tissues and cells (36). Thus, ROS are conventionally regarded as cytotoxic and mutagenic, and induce cell death, apoptosis and senescence in high levels (35). On the contrary, ROS also function as signaling molecules to mediate cell growth, migration, differentiation and gene expression in low levels (35). In the present study, matrine was demonstrated to induce cell apoptosis in NSCLC cells, then found to significantly induce ROS generation. These two combined with the finding that cell death and ROS generation were reversed by NAC, suggested that induction of ROS was one of the critical reasons causing cancer cell apoptosis by matrine.

Several downstream signaling pathways mediated by ROS were tracked, including MAP kinases (37), JAK/STAT (38), NF- $\mathrm{BB}$ (39), ion channels (40) and angiogenesis (41). Therefore, we also tried to explain whether matrine activates p38 by inducing ROS. As expected, using NAC to clear ROS could partially inhibit the level of phosphorylation of p38, indicating that MAPK/p38 was involved in matrine-induced cell apoptosis.

Collectively, the mechanism of matrine-induced NSCLC cell apoptosis was presented in this study. Matrine could stimulate ROS generation in NSCLC cells and subsequently activated p38, resulting in a caspase-dependent cell apoptosis by the indication of inhibition of $\mathrm{Bcl} 2$ and by activating caspase-3 and PARP. Matrine may be a promising agent for chemoprevention and treatment in NSCLC patients.

\section{Acknowledgements}

This study was supported by the Jiangsu University development foundation for clinical medicine (No. JLY20120171).

\section{References}

1. Jemal A, Siegel R, Xu J and Ward E: Cancer statistics, 2010. CA Cancer J Clin 60: 277-300, 2010.

2. Reungwetwattana T, Weroha SJ and Molina JR: Oncogenic pathways, molecularly targeted therapies, and highlighted clinical trials in non-small-cell lung cancer (NSCLC). Clin Lung Cancer 13: 252-266, 2012.

3. Ioannidis G, Georgoulias V and Souglakos J: How close are we to customizing chemotherapy in early non-small cell lung cancer? Ther Adv Med Oncol 3: 185-205, 2011.

4. Sadowska AM, Nowé V, Janssens A, Boeykens E, De Backer WA, and Germonpré PR: Customizing systemic therapy in patients with advanced non-small cell lung cancer. Ther Adv Med Oncol 3: 207-218, 2011.

5. Ancuceanu RV and Istudor V: Pharmacologically active natural compounds for lung cancer. Altern Med Rev 9: 402-419, 2004.

6. Azzam HS, Goertz C, Fritts M and Jonas WB: Natural products and chronic hepatitis C virus. Liver Int 27: 17-25, 2007.

7. Liu W, Tang JH and Wang YD: The research progress on Sophora flavescens Ait. Lishizhen Medicine and Materia Medica Research: 829-830, 2006 (In Chinese).

8. Zhang YL: Clinical study on matrine for the treatment of psoriasis. Hebei J Med Sci 69: 590-591, 1996 (In Chinese).

9. Liu M, Liu XY and Cheng JF: Advance in the pharmacological research on matrine. Zhongguo Zhong Yao Za Zhi 28: 801-804, 2003 (In Chinese).

10. Tan HR and Zhang BH: Experimental study of the anti-inflammatory effect of matrine. Zhong Xi Yi Jie He Za Zhi 5: 108-110, 69, 1985 (In Chinese). 
11. Chuang CY, Xiao JG and Chiou GC: Ocular anti-inflammatory actions of matrine. J Ocul Pharmacol 3: 129-134, 1987.

12. Liu JY, Hu JH, Zhu QG, Li FQ, Wang J and Sun HJ: Effect of matrine on the expression of substance $\mathrm{P}$ receptor and inflammatory cytokines production in human skin keratinocytes and fibroblasts. Int Immunopharmacol 7: 816-823, 2007.

13. Ma L, Wen S, Zhan Y, He Y,Liu X and Jiang J: Anticancer effects of the Chinese medicine matrine on murine hepatocellular carcinoma cells. Planta Med 74: 245-251, 2008.

14. Ho JW, Ngan Hon PL and Chim WO: Effects of oxymatrine from Ku Shen on cancer cells. Anticancer Agents Med Chem 9: 823-826, 2009.

15. Jiang H, Hou C, Zhang S, et al: Matrine upregulates the cell cycle protein $\mathrm{E} 2 \mathrm{~F}-1$ and triggers apoptosis via the mitochondrial pathway in K562 cells. Eur J Pharmacol 559: 98-108, 2007.

16. Zhang Y, Zhang H, Yu P, et al: Effects of matrine against the growth of human lung cancer and hepatoma cells as well as lung cancer cell migration. Cytotechnology 59: 191-200, 2009.

17. Li LQ, Li XL, Wang L, et al: Matrine inhibits breast cancer growth via miR-21/PTEN/Akt pathway in MCF-7 cells. Cell Physiol Biochem 30: 631-641, 2012.

18. Liu T, Song Y, Chen H, Pan S and Sun X: Matrine inhibits proliferation and induces apoptosis of pancreatic cancer cells in vitro and in vivo. Biol Pharm Bull 33: 1740-1745, 2010.

19. Chen K, Hu ZQ, Wang T, Guo JL, Guo H and Ye ZQ: Matrine inhibits the proliferation of prostate cancer cells and the activity of androgen receptor. Zhonghua Nan Ke Xue 14: 719-722, 2008 (In Chinese)

20. Chen K, Hu Z, Wang T, Guo H and Ye Z: Inhibitory effect of matrine on the expression of PSA and AR in prostate cancer cell line LNCaP. J Huazhong Univ Sci Technolog Med Sci 28 697-699, 2008

21. Zhou XH, Wei X, Huang ZS, et al: Effects of matrine on proliferation and telomerase activity of colon cancer SW1116 cells Zhong Yao Cai 32: 923-925, 2009 (In Chinese).

22. Yu P, Liu Q, Liu K, Yagasaki K, Wu E and Zhang G: Matrine suppresses breast cancer cell proliferation and invasion via VEGF-Akt-NF- $\kappa \mathrm{B}$ signaling. Cytotechnology 59: 219-229, 2009.

23. Lu J, Luo Q, Cheng P, Liu X, Bai M and Tu M: The role of matrine and mitogen-activated protein kinase/extracellular signal-regulated kinase signal transduction in the inhibition of proliferation and migration of human umbilical vein endothelial cells induced by lung cancer cells. Zhongguo Fei Ai Za Zhi 12 747-752, 2009 (In Chinese)

24. Zhu MY, Jiang ZH, Lu YW, Guo Y and Gan JJ: Matrine and anti-tumor drugs in inhibiting the growth of human lung cancer cell line. Zhong Xi Yi Jie He Xue Bao 6: 163-165, 2008 (In Chinese).

25. Saintigny $P$ and Burger JA: Recent advances in non-small cell lung cancer biology and clinical management. Discov Med 13: 287-297, 2012.

26. Aisner DL and Marshall CB: Molecular pathology of non-small cell lung cancer: a practical guide. Am J Clin Pathol 138: $332-346,2012$
27. Young LC, Campling BG, Cole SP, Deeley RG and Gerlach JH: Multidrug resistance proteins MRP3, MRP1, and MRP2 in lung cancer: correlation of protein levels with drug response and messenger RNA levels. Clin Cancer Res 7: 1798-1804, 2001.

28. Bunn PJ and Kelly K: New combinations in the treatment of lung cancer: a time for optimism. Chest 117 (Suppl 1): S138-S143, 2000.

29. Gori B, Ricciardi S, del Signore E, Fulvi A and de Marinis F: Oral tyrosine kinase inhibitors in the first-line treatment of advanced non-small cell lung cancer. Expert Opin Ther Targets 16 (Suppl 2): S55-S60, 2012.

30. Bradham C and McClay DR: p38 MAPK in development and cancer. Cell Cycle 5: 824-828, 2006.

31. Chang L and Karin M: Mammalian MAP kinase signalling cascades. Nature 410: 37-40, 2001

32. Johnson GL and Lapadat R: Mitogen-activated protein kinase pathways mediated by ERK, JNK, and p38 protein kinases. Science 298: 1911-1912, 2002.

33. Kumar P, Miller AI and Polverini PJ: p38 MAPK mediates $\gamma$-irradiation-induced endothelial cell apoptosis, and vascular endothelial growth factor protects endothelial cells through the phosphoinositide 3-kinase-Akt-Bcl-2 pathway. J Biol Chem 279: 43352-43360, 2004.

34. Park MT, Choi JA, Kim MJ, et al: Suppression of extracellular signal-related kinase and activation of p38 MAPK are two critical events leading to caspase-8- and mitochondria-mediated cell death in phytosphingosine-treated human cancer cells. J Biol Chem 278: 50624-50634, 2003.

35. Hancock JT, Desikan R and Neill SJ: Role of reactive oxygen species in cell signalling pathways. Biochem Soc Trans 29: 345-350, 2001.

36. Liou GY and Storz P: Reactive oxygen species in cancer. Free Radic Res 44: 479-496, 2010.

37. McCubrey JA, Lahair MM and Franklin RA: Reactive oxygen species-induced activation of the MAP kinase signaling pathways. Antioxid Redox Signal 8: 1775-1789, 2006.

38. Dixit D, Sharma V, Ghosh S, Koul N, Mishra PK and Sen E: Manumycin inhibits STAT3, telomerase activity, and growth of glioma cells by elevating intracellular reactive oxygen species generation. Free Radic Biol Med 47: 364-374, 2009.

39. Satriano J and Schlondorff D: Activation and attenuation of transcription factor NF- $\mathrm{B}$ in mouse glomerular mesangial cells in response to tumor necrosis factor-alpha, immunoglobulin $\mathrm{G}$, and adenosine 3':5'-cyclic monophosphate. Evidence for involvement of reactive oxygen species. J Clin Invest 94: 1629-1636, 1994

40. Matalon S, Hardiman KM, Jain L, et al: Regulation of ion channel structure and function by reactive oxygen-nitrogen species. Am J Physiol Lung Cell Mol Physiol 285: L1184-L1189, 2003.

41. Ushio-Fukai M and Nakamura Y: Reactive oxygen species and angiogenesis: NADPH oxidase as target for cancer therapy. Cancer Lett 266: 37-52, 2008. 